\title{
Malignant mesothelioma of the pleura: a study of 52 treated and 64 untreated patients
}

\author{
MR LAW, ANNA GREGOR, MARGARET E HODSON, HJG BLOOM, \\ M TURNER-WARWICK \\ From the Cardiothoracic Institute and Brompton Hospital and the Royal Marsden Hospital, London
}

ABSTRACT We have carried out sequential prospective studies of treatment with surgery alone, chemotherapy, and radiotherapy in malignant mesothelioma of the pleura. The survival of treated patients was contrasted with that of 64 contemporary untreated patients whose clinical condition at presentation was comparable with that of the treated patients. Non-radical surgery alone ( 28 patients) was of palliative benefit, particularly for the control of recurrent pleural effusions, and may have prolonged survival in one patient with localised malignant mesothelioma. Chemotherapy with doxorubicin, vincristine, and cyclophosphamide (12 patients, with preceding surgery in eight) was without objective benefit. Megavoltage radiotherapy by an off axis beam rotational technique (12 patients, with preceding surgery in eight) abolished pain and dyspnoea and may have prolonged survival in one patient and terminated recurrent pleural effusions in three, but it was of no value in the other patients. There was no significant difference in survival between treatment groups or between treated and untreated patients, and no difference when mesotheliomas of epithelial, sarcomatous, and mixed cell types were examined separately. Treatment of this disease appeared to fail because of the unresponsiveness of the tumour to existing forms of treatment and the advanced stage of the disease at clinical presentation.

Published reports of the treatment of malignant mesothelioma of the pleura (discussed below) give conflicting accounts of the efficacy of various forms of treatment in prolonging survival. A series of prospective pilot studies was therefore performed in two collaborating institutions (Brompton and Royal Marsden Hospitals). We report here the results of surgical resection alone, of combination chemotherapy, and of megavoltage radiotherapy, both preceded where feasible by surgery as a debulking manoeuvre. These studies were not designed on a formal randomised basis, but the survival of treated patients is compared with that of contemporary patients of physicians who gave symptomatic treatment only.

\section{Patients and methods}

There were 150 patients with malignant pleural mesothelioma managed at our two hospitals from

Address for correspondence: Dr ME Hodson, Cardiothoracic Institute, London SW3 6HP.

Accepted 16 December 1983
1971 to 1980 , of whom 116 were in good general condition at the time of diagnosis, and had no clinical evidence of extrathoracic disease. Certain physicians submitted such patients to active treatment as described below. The remaining physicians gave symptomatic treatment only. Adequate histological material, generally from thoracotomy or necropsy specimens, was available for all treated and untreated patients included in this study. The tumours were classified as epithelial or sarcomatous or of mixed histological types.' There were no significant differences in age, sex, asbestos exposure, or distribution of histological types between the three treated groups or between them and the untreated patients (table 1). All patients included in this study were in good clinical condition at the time of diagnosis; but computed tomography, performed in 32 of the treated patients, showed extensive intrathoracic disease, with widespread disease of the lateral chest wall in all, mediastinal disease in 29 , diaphragmatic disease in 28 , and lung invasion in 25 . Routine chest radiographs performed 6-18 months before the onset of symptoms were available for five patients and were normal.

Fifty two patients were submitted to active treat- 
Table 1 Details of treated and untreated patients

\begin{tabular}{|c|c|c|c|c|c|c|c|}
\hline \multirow[t]{2}{*}{ Treatment } & \multirow{2}{*}{$\begin{array}{l}\text { No of } \\
\text { patients }\end{array}$} & \multirow[t]{2}{*}{$M: F$} & \multirow{2}{*}{$\begin{array}{l}\text { Age (y): } \\
\text { mean (range) }\end{array}$} & \multirow{2}{*}{$\begin{array}{l}\text { No }(\%) \\
\text { exposed to } \\
\text { asbestos }\end{array}$} & \multicolumn{3}{|c|}{ Histological type (No (\%)) } \\
\hline & & & & & Epithelial & Sarcomatous & Mixed \\
\hline $\begin{array}{l}\text { Decortication alone } \\
\text { Chemotherapy } \\
\text { Radiotherapy } \\
\text { Untreated patients }\end{array}$ & $\begin{array}{l}28 \\
12 \\
12 \\
64\end{array}$ & $\begin{array}{c}21: 7 \\
12: 0 \\
9: 3 \\
50: 14\end{array}$ & $\begin{array}{l}56(39-74) \\
53(40-67) \\
55(36-70) \\
57(33-73)\end{array}$ & $\begin{array}{r}20(71) \\
11(92) \\
9(75) \\
46(72)\end{array}$ & $\begin{array}{r}15(54) \\
6(50) \\
7(58) \\
34(53)\end{array}$ & $\begin{array}{r}4(14) \\
4(33) \\
2(17) \\
14(22)\end{array}$ & $\begin{array}{r}9(32) \\
2(17) \\
3(25) \\
16(25)\end{array}$ \\
\hline
\end{tabular}

ment, and sequential prospective studies of the effect of surgery alone, chemotherapy, and radiotherapy were performed.

\section{SURGERY ALONE}

Non-radical parietal pleurectomy and decortication of the lung, removing the bulk of the tumour as discussed by Butchart et al, ${ }^{2}$ was performed in 44 patients. This was the only active treatment in 28 patients; in eight patients it preceded chemotherapy and in eight it preceded radiotherapy.

\section{CHEMOTHERAPY}

Twelve patients were treated with chemotherapy. Surgery was performed three to eight weeks beforehand in eight but was considered unjustified in four cases in which the diagnosis had already been established histologically. Cyclophosphamide $1 \mathrm{~g}$, doxorubicin $40 \mathrm{mg} / \mathrm{m}^{2}$, and vincristine $2 \mathrm{mg}$ were given intravenously for six courses. The first three courses were given at three weekly intervals and the last three courses at six weekly intervals.

\section{RADIOTHERAPY}

Twelve patients, all with unilateral disease confirmed by computed tomography, received high dose megavoltage radiotherapy. Eight of these had already undergone surgery. There was computed tomographic evidence of mediastinal disease in nine, diaphragmatic disease in eight, and lung invasion in five.

An off axis beam rotational radiotherapy technique was developed, modifying previously described field shaping work, ${ }^{3}$ with the aim of irradiating to a high dose a maximal area of the pleural space while shielding the underlying lung as much as possible. An $8 \mathrm{MeV}$ linear accelerator with isocentric $360^{\circ}$ rotational facility was used in all cases. Treatment volume was determined from computed tomographic scans performed under treatment conditions. This in turn determined the field size, the shielding, and the centre and arc of rotation for each patient. Dose distributions at the middle, proximal, and distal levels were obtained by the use of $\operatorname{Rad} 8$ and EMIPLAN 7000 computer planning systems. Phantom measurements for varying arcs of rotation and ratios of open to shielded fields were used to check the computer calculations. Individual treatment plans were verified with a Phillips Simulator. Modal doses of 5000-5500 cGy were delivered in 30-35 daily fractions over six to seven weeks. Doses to lung and spinal cord were kept within the limits of radiation tolerance.

\section{UNTREATED PATIENTS}

There were 64 patients also seen from 1971 to 1980 who did not receive active treatment because of the policy of their clinicians but who were comparable with the treated patients in terms of clinical condition and extent of disease at presentation.

A further 34 patients with mesothelioma who were in poor clinical condition at presentation were seen by the same physicians over the same period. These have not been included in this study.

\section{STATISTICAL ANALYSIS}

The survival of patients submitted to surgery alone, to chemotherapy, and to radiotherapy and that of untreated patients was analysed by comparison of standard errors of survival probabilities at six monthly intervals to five years.

\section{Results}

\section{SURGERY}

Thoracotomy showed diffuse tumour of the costal pleura in all but one patient, with frequent disease of the mediastinal and diaphragmatic pleura and invasion of the lung. Localised malignant mesothelioma (of sarcomatous cell type) was found in one case in which six discrete pleural tumours attached to the parietal pleura and infiltrating the diaphragm were excised widely.

Surgery produced symptomatic benefit in some patients. Recurrent pleural effusions had occurred in 25 of the surgically treated patients and were abolished by decortication in 22 of these. Many patients reported improvement in pain and dyspnoea for a few weeks or months, although little or no palliation was achieved in patients who had more severe pain before operation. Postoperative deaths (three cases) and wound infections occurred only in those patients with more extensive disease. Subsequent tumour deposits in thoracotomy scars were 
Table 2 Comparison of survival in treated and untreated patients

\begin{tabular}{|c|c|c|c|c|c|}
\hline \multirow[t]{2}{*}{ Treatment } & \multirow{2}{*}{$\begin{array}{l}\text { No of } \\
\text { patients }\end{array}$} & \multirow{2}{*}{$\begin{array}{l}\text { Median } \\
\text { survival } \\
(m)\end{array}$} & \multicolumn{3}{|c|}{ No (\%) surviving (from onset of symptoms) } \\
\hline & & & $1 y$ & $2 y$ & $4 y$ \\
\hline $\begin{array}{l}\text { Decortication alone } \\
\text { Chemotherapy } \\
\text { Radical radiotherapy } \\
\text { Untreated patients }\end{array}$ & $\begin{array}{l}28 \\
12 \\
12 \\
64\end{array}$ & $\begin{array}{l}20 \\
19 \\
18 \\
18\end{array}$ & $\begin{array}{r}23(82) \\
9(75) \\
12(100) \\
49(77)\end{array}$ & $\begin{array}{r}9(32) \\
4(33) \\
4(33) \\
20(31)\end{array}$ & $\begin{array}{l}3(11) \\
0 \\
1(8) \\
7(11)\end{array}$ \\
\hline
\end{tabular}

documented in 17 cases, but these never ulcerated and were generally not associated with pain or tenderness.

Survival from the onset of symptoms of the 28 patients submitted to surgery alone was from eight months to eight years (median 20 months) (table 2). The patient with localised mesothelioma survived six years after surgery and was symptom free for five years.

\section{CHEMOTHERAPY}

Of the 12 patients (eight of whom had prior surgery), seven received six courses of combined cyclophosphamide, doxorubicin, and vincristine. In five cases treatment was stopped after three to four courses because of side effects and progression of disease despite treatment. No objective response was observed. There was worsening of pain and dyspnoea and radiological progression of disease in all cases. Ten of the 12 patients died within nine months of completing chemotherapy, one after 15 months and one after 22 months. Survival from onset of symptoms was from nine to 32 months (median 19 months). There were no major complications of chemotherapy, but all patients experienced nausea, vomiting, and alopecia.

\section{RADIOTHERAPY}

Of the 12 irradiated patients (eight of whom had prior surgery), 11 showed little or no improvement. There was no pain relief in nine of these 11 patients; in three pain worsened during radiotherapy. Two patients reported some pain relief, but neither had severe pain initially. Dyspnoea did not improve. One patient developed severe pain and a large skin deposit below the irradiated area; further radiotherapy produced regression of the skin deposit but no pain relief. Cutaneous deposits in three untreated patients did not regress. Computed tomographic scans and chest radiographs repeated after radiotherapy in these 11 patients showed no regression of disease. Survival after completion of treatment ranged from three to 10 months in the 11 patients.

One patient, a 30 year old woman with no history of asbestos exposure and a tumour of epithelial cell type, showed a dramatic response to radiotherapy. Recurrent effusions ceased, and pain and dyspnoea abated; she gained weight and there was radiological improvement. She remains well and active four years after completion of treatment. Radiotherapy also terminated recurrent pleural effusions in two other cases.

In the 12 irradiated patients survival from onset of symptoms was from 14 months to five years (median 18 months). Complications of radiotherapy were minimal, with nausea and malaise in six, transient radiation hepatitis in one, and mild oesophagitis in

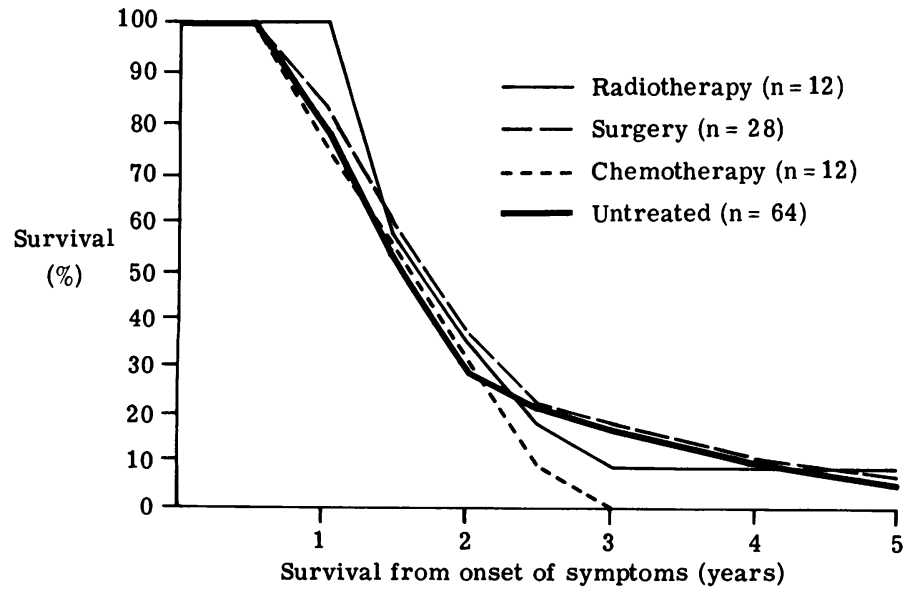

Actuarial survival curves of patients treated by surgery, radiotherapy, and chemotherapy and of untreated patients. 
one. Six patients had no side effects; none developed radiation pneumonitis. In three patients tumour of the contralateral pleura, which had not been evident on chest radiographs or computed tomographic scans before treatment, became manifest shortly after the completion of radiotherapy.

\section{UNTREATED PATIENTS}

Median survival from the onset of symptoms in the group of 64 untreated patients was 18 months. Survival exceeded four years in seven of the untreated patients and five years in four; one patient survived 16 years. There was no significant difference in survival between the untreated patients and the patients submitted to decortication alone, chemotherapy, or radiotherapy (table 2 and fig). Subdivision of the cases into epithelial, sarcomatous, and mixed cell types showed no difference in survival between treated and untreated cases of each cell type.

\section{Discussion}

Assessment of the value of any form of treatment in mesothelioma is difficult. Because the tumour is seen uncommonly in most centres it would require many years to recruit sufficient patients to conduct a randomly allocated controlled trial, and no such trial has yet been reported. In the present study the survival of treated patients is compared with that of contemporary untreated patients, selection for active treatment therefore being determined at the time of referral.

Complete surgical removal of tumour in diffuse malignant mesothelioma is not possible, but prolonged survival as a result of subtotal resection has been claimed. Two recent series of surgically treated patients $^{4}$ and some less recent series reviewed by Legha and Muggia ${ }^{6}$ have all featured some long survivors. Other studies reported no benefit from surgery. ${ }^{7-12}$ It has been suggested recently that radical surgery including pleuropneumonectomy may prolong survival ${ }^{213}$ but review of older series has shown little benefit and high morbidity. ${ }^{614-16}$ In the present study the surgically treated patients did not survive longer than untreated patients, although resection may have prolonged the survival of the one patient with a localised malignant mesothelioma. In a series of eight cases of localised malignant mesothelioma none were cured by resection but one survived nine years and another three years. ${ }^{17}$

We observed no response to chemotherapy. Previous studies of the effect of chemotherapy have been well summarised. 6141518 Partial and complete responses with prolonged survival have been claimed, and doxorubicin and vincristine are considered the most useful agents. ${ }^{4613-1518-21}$ Retrospective reviews, however, have generally reported chemotherapy to be of no value..$^{-1222-25}$

Mesothelioma is generally considered a radioresistant tumour, and few reports have claimed response to radiotherapy. ${ }^{14}$ Eschwege and Schlienger ${ }^{26}$ radically irradiated 14 patients, with a median survival after treatment of 15 months. Antman and her coworkers ${ }^{47}$ described one five year survivor out of five patients given megavoltage radiotherapy; as in our study, the one long survivor was a young woman with no history of asbestos exposure. Retrospective analysis has shown no apparent prolongation of survival from orthovoltage radiotherapy. ${ }^{7-1022-24}$ It is difficult to irradiate the pleural space to a high dose without exceeding the radiation tolerance of the underlying lung. Our megavoltage technique allowed for this, but resulted in probable prolongation of survival in only one patient. Difficulty in detecting and controlling contralateral disease at an early stage further limited the value of radical radiotherapy.

Published reports of apparent prolongation of survival in a minority of treated patients may be of limited significance. Mesothelioma can be difficult to distinguish from other malignant tumours with small biopsy samples. Few prospective studies have included a suitable group of untreated patients for comparison of survival. Selection of patients for active treatment, both by investigators and by referring physicians, favours longer survival and invalidates comparisons between treated and untreated cases. Our study confirmed previous reports ${ }^{91214}$ of occasional prolonged survival of untreated patients, with little or no early clinical deterioration; in treated patients this may be falsely attributed to the effects of treatment. We have noticed occasional symptomatic response to radiotherapy with mesothelioma of epithelial but not sarcomatous cell type. ${ }^{1}$ The present study did not confirm claims of possible prolongation of survival by treatment of epithelial tumours, ${ }^{51624}$ which have a longer natural history than tumours of other cell types. ${ }^{1791323}$ The number of patients with definite prolongation of survival by treatment is very small, and there has been no report of cure. ${ }^{14}$

It has been suggested that regular screening of asbestos workers may lead to earlier diagnosis and more effective treatment of mesothelioma. ${ }^{15}$ Routine chest radiographs taken six to 18 months before the onset of symptoms in five of our patients were normal, suggesting that radiological evidence of tumour precedes the onset of symptoms by only a few months. The interval between the development of radiological and clinical features of contralateral 
pleural disease was also short. The tumour must be regarded as being resistant to existing forms of treatment; but extensive intrathoracic disease at clinical presentation, as determined from computed tomographic scans and thoracotomy findings in the present study, and the difficulty in detecting disease radiologically at an early stage are also important reasons for failure of treatment.

Non-radical surgery does not prolong survival, but does provide abundant tissue for histological diagnosis, and was of palliative benefit, particularly for the control of recurrent pleural effusions, in both the present and previous studies. ${ }^{214}$ Complications of surgery were infrequent in patients with less extensive disease and, unlike others, ${ }^{7825}$ we did not encounter pain or other clinical problems associated with tumour deposits in thoracotomy scars. At present, however, the few patients who may benefit from chemotherapy or radiotherapy cannot be identified at diagnosis, and the side effects of treatment and length of time spent in hospital must be considered. More effective cytotoxic agents are needed. The development of a xenograft model $^{28}$ using human mesothelioma tissue transplanted into nude or immune deprived mice may facilitate the screening of new agents and the investigation of the timing and optimum sequence of treatment of different modalities.

We wish to thank all our clinical colleagues at the Brompton and London Chest Hospitals and referring hospitals whose patients have formed the basis of this study.

\section{References}

' Law MR, Hodson ME, Heard BE. Malignant mesothelioma of the pleura: relationship between histological type and clinical behaviour. Thorax 1982;37:810-5.

${ }^{2}$ Butchart EG, Ashcroft T, Barnsley WC, Holden MP. The role of surgery in diffuse malignant mesothelioma of the pleura. Semin Oncol 1981;8:321-8.

${ }^{3}$ Proimos BS. Shaping the dose distribution through a tumor model. Radiology 1969;92:130-5.

${ }^{4}$ Antman KH, Blum RH, Greenberger JS, Flowerdew G, Skarin AT, Canellos GP. Multimodality therapy for malignant mesothelioma based on a study of natural history. Am J Med 1980;68:356-62.

${ }^{5}$ Wanebo HJ, Martini N, Melamed MR, Hilaris B, Beattie EJ. Pleural mesothelioma. Cancer 1976;38:2481-8.

' Legha SS, Muggia FM. Therapeutic approaches in malignant mesothelioma. Cancer Treat Rev 1977;4:13-23.

' Elmes PC, Simpson MJC. The clinical aspects of mesothelioma. $Q J$ Med 1976;45:427-49.
${ }^{8}$ Shearin JC, Jackson D. Malignant pleural mesothelioma. J Thorac Cardiovasc Surg 1976;71:621-7.

9 Brenner J, Sordillo PP, Magill GB, Golbey RB. Malignant mesothelioma of the pleura. Cancer 1982;49:2431-5.

${ }^{10}$ Borow M, Conston A, Livornese L, Schalet N. Mesothelioma following exposure to asbestos: a review of 72 cases. Chest 1973;64:641-6.

" Lewis RJ, Sisler GE, Mackenzie JW. Diffuse mixed malignant pleural mesothelioma. Ann Thorac Surg 1981;31:53-60.

12 Whitwell F, Rawcliffe RM. Diffuse malignant pleural mesothelioma and asbestos exposure. Thorax 1971;26:6-22.

${ }^{13}$ Chahinian AP, Pajak TF, Holland JF, Norton L, Ambinder RM, Mandel EM. Diffuse malignant mesothelioma - prospective evaluation of 69 patients. Ann Intern Med 1982;96:746-55.

${ }^{14}$ Chahinian AP, Holland JF. Treatment of diffuse malignant mesothelioma: a review. Mt Sinai $J$ Med 1978;45:54-67.

is Aisner J, Wiernik PH. Malignant mesothelioma - current status and future prospects. Chest 1978;74:43844.

${ }^{16}$ Butchart EG, Ashcroft T, Barnsley WC, Holden MP. Pleuropneumonectomy in the management of diffuse malignant mesothelioma of the pleura. Thorax 1976;31:15-24.

${ }^{17}$ Okike N, Bernatz, PE, Woolner LB. Localised mesothelioma of the pleura - benign and malignant variants. J Thorac Cardiovasc Surg 1978;75:363-72.

${ }^{18}$ Aisner J, Wiernik PH. Pleural mesotheliomas - clinical experience with 37 patients. $A J R$ 1967;99:863-80.

19 Yap BS, Benjamin RS, Burgess MA, Bodey GP. The value of adriamycin in the treatment of diffuse malignant pleural mesothelioma. Cancer 1978;42:1692-6.

20 Jett JR, Eagan RT. Chemotherapy for malignant mesothelioma. CAMEO. Am J Clin Oncol 1982;5:429-31.

${ }^{21}$ Dimitrov NV, Egner J, Balcueva E, Suhrland LG. High dose methotrexate with citrovorum factor and vincristine in the treatment of malignant mesothelioma. Cancer 1982;50:1245-7.

${ }^{22}$ Taryle DA, Lakshminarayan S, Sahn SA. Pleural mesothelioma - an analysis of 18 cases and review of the literature. Medicine (Baltimore) 1976;55:153-62.

${ }^{23}$ Oels HC, Harrison EG, Carr DT, Bernatz PE. Diffuse malignant mesothelioma of the pleura: a review of 37 cases. Chest 1971;60:564-70.

${ }^{24}$ Ratzer ER, Pool JL, Melamed MR. Pleural mesotheliomas - clinical experience with 37 patients. A J R 1967;99:863-80.

${ }^{25}$ Dorward AJ, Stack BHR. Diffuse malignant pleural mesothelioma in Glasgow. $\mathrm{Br} J$ Dis Chest 1981;75:397-402,

${ }^{26}$ Eschwege F, Schlienger M. La radiotherapie des mesotheliomes pleuraux malins. $J$ Radiol 1973;54:255-9.

${ }^{27}$ Gordon W, Antman KH, Greenberger JS, Weichselbaum RR, Chaffey JT. Radiation therapy in the management of patients with mesothelioma. Int $J$ Radiat Oncol Biol Phys 1982;8:19-25.

${ }^{28}$ Chahinian AP, Beranek JT, Suzuki Y, et al. Transplantation of human malignant mesothelioma into nude mice. Cancer Res 1980;40:181-5. 